\title{
Rhetorical Culture and Brand Slogan: An Analysis of the Slogans of all Commercial Banks from Nepal
}

\author{
Yog Raj Lamichhane*
}

DOI: https://doi.org/10.3126/jnbs.v14i1.41487

Accepted on 20 October 2021

\begin{abstract}
Rhetoric is the artful deviation of information and ideas. It is commonly utilized in different forms of advertising. In this context, the study has examined how rhetorical devices are employed in the brand slogans of the 28 commercial banks in Nepal. To achieve their dominant theme there, it identifies and categorizes the devices following the taxonomy developed by James H. Leigh. The framework divides such figures of speech into 4ltypes under 2 major categories schemes and tropes. The finding from this descriptive analysis and has indicated that music, memory, association, emphasis, emotion and exaggeration are some popular constructs for designing the slogans. Moreover, Nepali private commercial banks seem more successful in utilizing such strategies as they have applied maximum rhetorical devices in comparison to foreign joint venture and governmental banks. In this trajectory, foreign joint-venture banks have an international brand in the name itself, governmental banks can communicate with customers being people's banks and private banks appear smart in incorporating maximum wordplays in the slogans to play with the sentiment of the audience influencing them. The study simultaneously contributes to both the fields of creative writing and marketing communication literary world and marketing sector updating the current awareness about rhetorical culture. The study has only included the slogans of commercial banks from Nepal, but the comparative study between the slogans of all the banks from Nepal and the banks' slogans from other countries may reflect a clearer picture regarding rhetorical culture.
\end{abstract}

Keywords: Brand slogan, rhetoric, schemes, tropes, figures of speech, bank

\section{INTRODUCTION}

Particularly in the age of mass media and capitalism, a person can hardly escape advertising and "it is not unusual for an infant's first spoken sentence to be an advertising jingle from television" (Harris et al., 1986, p. 1). It is said in the last quarter of the twentieth century in the Western context but the massive globalization and extensive media make it common throughout globe. Such advertising also appears in a form of brand slogan informing the customer about the brand and drives them to diverse products and services in a concise and catchy form.

\footnotetext{
* Mr. Lamichhane is an Assistant Professor at School of Business, Pokhara University. He is currently an M.Phil. scholar at the Central Department of English, TU.

Email: lcyograj@gmail.com / lcyograj@pu.edu.np

40
} 
According to O'Guinn, T. C., Allen and Semenik, "slogans are short phrases that help establish a brand identity but are mainly used to increase memorability for the brand" (as cited in Miller \& Toman, 2014, p. 2). As people can hardly escape advertising, it can scarcely escape language- the rhetorical language. Harris et al. (1986) believe that the fundamental decision in marketing concerning language is choosing the name and slogan of a particular product or service. While developing slogans, different rhetorical devices are used to inflate the remembrance. Therefore, memorability becomes an incomparable essence in brand slogans (Musté et al., 2015).

Both market and democracy are believed to work through influencing other, not the coercion to get success. For this, the involved parties should have strong excess not only in information but also in language to win the heart and mind, which supports to maintain brand awareness by inviting consumers to the specific service and product (Quelch \& Jocz, 2007). In this sagacity, slogans are an effective tool to achieve the above-mentioned goals effectively in an economized way.

In addition, rhetoric is a crafty process to achieve persuasion. In so, the brand slogans are directly associated with customers, but much attention is not given to that (Denton, 1980). That is why slogans are expected to be designed in such a way that they make a direct connection to social life with persuasive power. It is assumed, "Ad text functions as a dramatic monologue revealing the company soul, and attracting the desired consumer as soul-mate" (Stern, 1988). In this regard, the brand slogans are often full of figures of speech and they mutely serve the function of music animating the objects and concepts in advertising (Durgee,1987). Consequently, rhetoric serves as a soul for the brand slogans in advertising.

In the market, people encounter brand slogans everywhere. These slogans are not only a powerful source to draw attention, but they are also successful to drive customers to the product and service. Moreover, the slogans, which are heavily loaded with figures of speech, are not just tools for persuasion to establish relationship with customer, but a matter to be decoded for further interpretations.

Thus, the study aims to decode the slogans of Nepali commercial banks to identify the logical pattern and dominant theme there. The specific objectives of the study are: a) to explore the rhetorical devices for the possible categorization and inferences b) to explore the potential logic and dominant theme applied in the slogans by the copywriters behind choosing such rhetorical strategies. For this rhetorical diagnosis, the taxonomy developed by Leigh (1994) to study figures of speech in print ad headlines assumes to be effective and reliable. Various researches have used this framework at different times. Monsefi and Mahadi (2016) have recently used the same taxonomy in a study of figure of speech in English online news headlines and it is adopted in this study as a theoretical framework to decode the rhetoric used by the commercial banks in Nepal. Leigh (1994) lists 41 figures of speech under schemes and tropes. The schemes are figures of speech with grammar structure deviated from the usual word pattern dealing with the word order, grammar, letters, and sounds, rather than word meaning and it is achieved through word order- coordinated, deliberate word omissions and insertions, repetitions, and rhymes. Moreover, the tropes are the artistic deviations of the simple language. In the light of these 41 figures, all the brand slogans of commercial banks from Nepal have been scrutinized to reveal the rhetorical culture.

\section{LITERATURE REVIEW}

The short verbal content of a brand slogan is expected to be concise enough and tell many things economically. In this regard, the distinctive feature of any brand slogan as a form of advertising is its capability to convey more than how it looks there. The developer of the slogan anticipates the certain qualities in it, among then, at least one linguistic device to make it 
persuasive and memorable (Miller \& Toman, 2014). In another word, it carries the philosophy of the brand. For the sake of brevity, most slogans use less verbal signs and symbols. However, simplicity and brevity are not enough here. Lagerwerf (2002) presenting the result related to conscious ambiguity in slogans, explains that moderate syntactic or semantic complexity leads to better recall than so simple one. In creating deeper memory among the customers through stylistic complexity, sometimes it may create confusion and achieve adverse effects. Anyway, these slogans even have a role in brand extension dragging the same customer to a new product (Pryor \& Brodie, 1998). Therefore, it is not the brand, which creates a slogan. Yet, the slogan expands a brand too.

In designing a particular slogan, there might be an excessive presence of specific devices but there is no syndicate of singular category. Generally, there appear both tropes and schemes in different proportions.

Regarding rhetorical devices, the result of the study of Leigh related to advertising has revealed pun, assonance and alliteration as the most repetitive figures of speech (1994). The content analysis of 2183 print advertisements with headlines evaluates the multiplicity of the figures and exposes a "combination of a trope and a grammar figure, but multiple grammar figures are also fairly common" (Leigh, 1994, p. 31). Similarly, a recent study by Iswati and Widodo (2020) identifies schemes as the most repeated devices and among them, the asyndeton has appeared much. The deliberate word omissions and insertions become property in slogans when they are utilized in playful manner.

Contrary to the result of the study, there is another study on wordplay in English online news headlines by Monsefi and Mahadi (2016) that reveals tropes as the most repeated rhetorical devices in which metonymy covers the larger space. It shows that there is no monopoly in applying particular types of wordplay in slogans. Following the legacy of Leigh to identify the rhetorical choices in slogan, among phonetic, semantic and syntactic schemes and tropes, a study of Miller and Toman (2014) establishes:

Schemes seem to appear more often than tropes. Perhaps, schemes are favored because they are easier to construct than are the latter... The most commonly used phonetic devices were alliteration, consonance, assonance, the initial plosive. Word/phrase repetition was the most commonly appearing syntactic device. Among the semantic devices, metaphor, metonymy, pun, self-reference, and well-known phrase appeared most often. (p.15)

A grammatical structure is easier than a semantic and conquers the space in rhetorical culture related to brand slogans without illuminating others. All these studies have established the extensive role of schemes in compression to tropes in designing rhetorical slogans, but none of them has downsized the inevitable role of both for strengthening the intensity of the slogan among audience.

There appear slogans in the market or in media related to different brands to enhance images, aid recognition, and create differentiation. Kohli et al. (2007) enforce that slogans identify the brands and they are highly contributive for brand equity especially helping to recall the brands. When considering the idea of previous study, strong sound patterning in slogans forcefully contributes to creating tough brand equity. Ambiguity also adds meaning in slogans if customer can recognize it. Discussing ambiguity and unambiguity in one side and recognition and unrecognition in another, Lagerwerf (2002) deduces the ideas, where comprehensive slogans are valued much in comparison to vague one, but simultaneously recognized ambiguity is loved in comparison to both unambiguous and unrecognized slogans, recognized ambiguous slogans are appreciated more than unrecognized ambiguous slogans. Thus, intentionally confusing slogans are valued extremely than other slogans. Ambiguity is a major asset of such slogan, it is noted that 
appreciation of the slogan is linked with reorganization and resolving the inserted multiplicity created in the form of ambiguity.

Along with ambiguity, while discussing rhetoric one can hardly leave to discuss metaphor. Morgan and Reichert (1999) relate the dominant interest of scholars and practitioners in metaphor that demands deeper level of understanding for detection. The metaphors match up two objects even though on the face they appear to be quite diverse. Metaphor, ambiguity and sound pattern as strengths of any slogans help to heighten the brand equity sensitizing audience to participate in recognizing latent meaning. However, only the recognition of such meaning makes the slogan effective.

Rhetoric always searches for an effective way to articulate an idea in given circumstances altering the expression to suit the designated situation. McQuarrie and Mick (1996) believe that not all the potentialities of rhetorical techniques have been incorporated by advertising theories. It calls to introduce the hidden treasures, which are in form of rhetoric of promotion. As McQuarrie and Mick (1996) suggest, "If consumers do not have to read an ad then one had best motivate that reading. If consumers will only skim an ad, then one must make it memorable at a glance. Rhetoric integrates and explains stylistic devices that may be used to accomplish these and related goals" (p. 435). The inclusion of rhetorical devices possibly solves the problem of avoiding advertising in the market.

Brands, brand slogans and brand awareness are associated concepts. As a tool of brand awareness, slogan adjoins certain products or services to their users employing the power of rhetoric. Evaluating the pragmatic aspects of airport and car advertising, Michalik and MichalskaSuchanek (2016) emphasize rhetorical plan of the copywriters as a strategic choice of words for an appealing audience. Slogans play a crucial role to draw the attention and interest of the prospective customers symbolically signaling the benefits.

Issues and fields might be different in diverse studies concerning advertising writing but no study, specially reviewed for this research, has disregarded the inevitable role of rhetoric as a vital ingredient for brand equity. However, virtually no study has been done being specific in the Nepali context collecting local slogans. Therefore, this study decodes the brand slogans of 28 commercial banks from Nepal. It identifies the rhetorical devices in the slogans and analyzes their pattern for the possible categorization and interpretation that becomes a guideline for developing enchanting brand slogans in the days to come.

\section{METHODOLOGY}

The study has adopted a descriptive research design to identify the pattern of rhetorical culture among 28 advertising slogans of all commercial banks from Nepal. It identified the categories, calculated the frequencies, analyzed the trends and described the characteristics concerning selected slogans. Disregarding the possible increase or decrease of the numbers of the commercial bank and the changes in slogan within the period of the study, it has included the banks and slogans that were in existence at the time of the data collection. It took only one official brand slogan from the official website of each bank. To avoid confusion in identifying the leading brand slogans, the researcher has consulted the concerned officials of such banks. Out of 28 slogans, 16 were in English language and the remaining 12 were in Nepali. The slogans, which were in Nepali language, were translated into Roman English for analysis to grasp the real essence and organic meaning. They were also literally translated into English for universal readership.

The aforementioned framework developed by Leigh (1994) was exercised objectively to present and analyze the data. Leigh had developed this framework separating 41 figures of speech mainly into two categories of tropes and schemes. They represent two distinct modes of proper deviation. "Both schemes and tropes entail a shift of some kind: a trope involves a shift of 
meaning i.e. it operates at the conceptual or semantic level, a scheme involves a shift of order i.e. it operates at the physical or sensory level of the language structure" (Christopher, 2013, p. 773). There were 20 and 21 sub-categories of schemes and tropes respectively. See the Appendix for all 41 rhetorical figures. In the beginning, the study has identified the embedded rhetorical devices from the slogans. After that, they were classified into different categories and sub-categories for the frequency calculation. Finally, the study has discussed and interpreted to detect the rhetorical pattern of the banking slogans.

\section{RESULTS}

\subsection{List of the Commercial Banks and their Slogans}

Table 1 presents the name of 28 commercial banks and their brand slogans. The slogans, which are italicized, are originally in Nepali language. They are rewritten in Roman English for actual analysis.

\section{Table 1}

List of the Commercial Banks from Nepal and their Brand Slogans

\begin{tabular}{|c|c|c|}
\hline S.N. & Commercial Banks & Brand Slogans \\
\hline 1 & Nepal & Nepalko Pahilo Bank (Nepal's First Bank) \\
\hline 2 & Citizens International & Your Partner For Progress \\
\hline 3 & Kumari & Sabaika Lagi Sadhaika Lagi (For All, For Always) \\
\hline 4 & Civil & Thinking Forward, Moving Forward \\
\hline 5 & Sunrise & Together We Can Build \\
\hline 6 & Nepal SBI & $\begin{array}{l}\text { Bishuddha Banking...Aru Kehi Hoina } \\
\text { (Pure Banking... Nothing other) }\end{array}$ \\
\hline 7 & Nepal Credit and Commerce & Your Business Bank \\
\hline 8 & Everest & ...the name you can BANK upon! \\
\hline 9 & Nepal Investment & Truly A Nepali Bank \\
\hline 10 & Prime & Sharing dreams, Changing Lives. \\
\hline 11 & NIC Asia & Bank Pani, Saathi Pani (A Bank too, A Friend too) \\
\hline 12 & Rastriya Banijya & ... Tapaiko Aafnai Bank (...your Own Bank) \\
\hline 13 & Himalayan & The Power to Lead \\
\hline 14 & Prabhu & Power to Succeed \\
\hline 15 & Janata & $\begin{array}{l}\text { Nepali Janatako Bank, Janata Bank } \\
\text { (Nepali Citizens' Bank, Janata Bank) }\end{array}$ \\
\hline 16 & Century & Saral Banking, Sabaiko Lagi (Simple Banking for All) \\
\hline 17 & Laxmi & Sabal Aadhunik Uttardayi (Efficient Advanced Accountable) \\
\hline 18 & Bank of Kathmandu & We make your life easier \\
\hline 19 & Global IME & Sabaika Lagi Bank (Bank for All) \\
\hline 20 & Siddhartha & Bank for Your Prosperity \\
\hline 21 & Nabil & Together Ahead \\
\hline 22 & Nepal Bangladesh & The Bank for Everyone \\
\hline 23 & N.M.B. & Move Beyond \\
\hline 24 & Machhapuchchhre & Service with a Personal Touch \\
\hline 25 & Sanima & Sawal ani Bishwasaniya (Capable and Trustworthy) \\
\hline 26 & Agricultural Development & Tapai Hamro Ghar Aaganko Bank (Bank of our Locality) \\
\hline 27 & Standard Chartered & Here for good \\
\hline 28 & Mega & Halo Dekhi Hydro Samma (From Plough to Power) \\
\hline
\end{tabular}

Note. The contents in the brackets are the literal translation of the slogans, which are originally in Nepali Language and translated into English for general comprehension. 


\subsection{Brand Slogans and the Rhetorical Devices Used there}

Similarly, table 2 proves the list of slogans and the embedded rhetorical devices there. In the light of the selected theoretical framework, the study has id333entified 68 usages of rhetorical devices. Among them, only 13 types of schemes and 8 types of tropes are used in 25 slogans. No such devices are detected in three banking slogans.

\section{Table 2}

List of the Brand Slogans and the Embedded Rhetorical Devices there

\begin{tabular}{|c|c|c|}
\hline S.N. & Slogans & Devices \\
\hline 1 & Nepalko Pahilo Bank & Syllepsis \\
\hline 2 & Your Partner For Progress & $\begin{array}{l}\text { Alliteration, Personification, Metaphor } \\
\text { and Internal Rhyme }\end{array}$ \\
\hline 3 & Sabaika Lagi Sadhaika Lagi & $\begin{array}{l}\text { Alliteration, Asyndeton, Epistrophe, } \\
\text { Parallelism Repetition and End Rhyme }\end{array}$ \\
\hline 4 & Thinking Forward, Moving Forward & $\begin{array}{l}\text { Asyndeton, Alliteration, End Rhyme, Epistrophe, } \\
\text { Parallelism, Personification and Repetition }\end{array}$ \\
\hline 5 & Together We Can Build & Anastrophe \\
\hline 6 & Bishuddha Banking...Aru Kehi Hoina & Alliteration, Litotes, Periphrasis and Ellipsis \\
\hline 7 & Your Business Bank & Alliteration \\
\hline 8 & ...the name you can BANK upon! & Anthimeria, Assonance, and Ellipsis \\
\hline 9 & Truly A Nepali Bank & Anastrophe and Internal Rhyme \\
\hline 10 & Sharing dreams, Changing Lives. & $\begin{array}{l}\text { Asyndeton, Personification, End Rhyme, } \\
\text { Parallelism and Hyperbole }\end{array}$ \\
\hline 11 & Bank Pani, Saathi Pani & $\begin{array}{l}\text { Epistrophe, Personification, Metaphor, } \\
\text { Parallelism, End Rhyme and Repetition }\end{array}$ \\
\hline 12 & ... Tapaiko Aafnai Bank & Ellipsis \\
\hline 13 & The Power to Lead & Hyperbole and Metaphor \\
\hline 14 & Power to Succeed & Hyperbole and Metaphor \\
\hline 15 & Nepali Janatako Bank, Janata Bank & $\begin{array}{l}\text { Polyptoton, Asyndeton, Alliteration and } \\
\text { Repetition }\end{array}$ \\
\hline 16 & Saral Banking, Sabaiko Lagi & Asyndeton, Alliteration, and Parallelism \\
\hline 17 & Sabal Aadhunik Uttardayi & Parallelism and Climax \\
\hline 18 & We make your life easier & Hyperbole and Internal Rhyme \\
\hline 19 & Sabaika Lagi Bank & No device \\
\hline 20 & Bank for Your Prosperity & Hyperbole \\
\hline 21 & Together Ahead & No device \\
\hline 22 & The Bank for Everyone & Ellipsis \\
\hline 23 & Move Beyond & Hyperbole \\
\hline 24 & Service with a Personal Touch & No device \\
\hline 25 & Sawal ani Bishwasaniya & Climax \\
\hline 26 & Tapai Hamro Ghar Aaganko Bank & Imagery, End Rhyme, Parallelism and Syllepsis \\
\hline 27 & Here for good & Internal Rhyme \\
\hline 28 & Halo Dekhi Hydro Samma & Alliteration, Parallelism and Antithesis \\
\hline
\end{tabular}




\subsection{Number of Devices Used by Different Commercial Banks}

The number and percentage of the rhetorical devices used by different types of commercial banks and further division of such devices into schemes and tropes reflect the domination of domestically owned private banks over governmental and foreign joint venture and schemes over tropes.

\section{Figure 1}

Percentage and Number of the Devices Used By Three Types of Commercial Banks

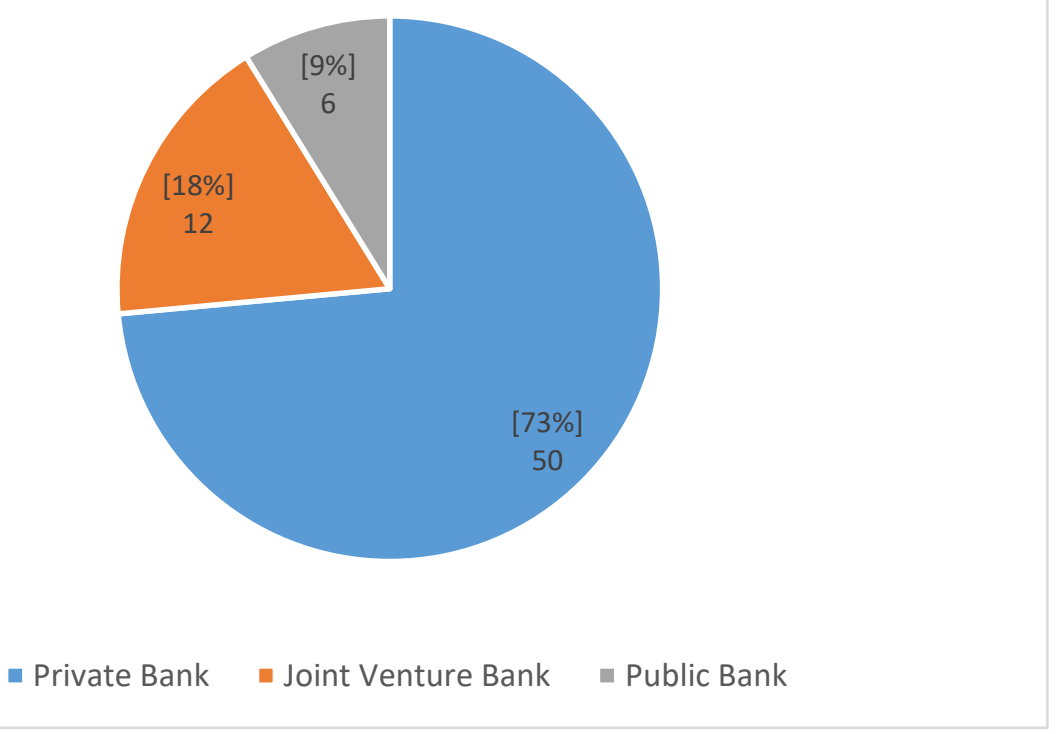

Out of 68 usages of rhetorical devices by 28 Nepali commercial banks, private Nepali commercial banks have utilized the device 50 times in their slogan, which becomes about 73 percent of the total usage but they cover about 64 percent of banks in terms of number. The foreign joint-venture commercial banks are exactly 25 percent in number and consumed 18 percent usage of the devices in their slogans. Finally, the governmental commercial banks cover 10 percent of the total commercial banks and use nearly nine percent of total usages of the devices.

\subsection{Group of 10 Banks Using Maximum Rhetorical Devices}

Figure 2 reflects ten banks, which have utilized maximum rhetorical devices in their slogan. There is the inclusion of all three categories of Nepali commercial banks: public, foreign joint venture and domestically owned.

Among 28 commercial banks from Nepal, Global IME, Machhapuchchhre and Nabil bank do not have rhetorical devices in their slogan. It comes under just about 11 percent. Out of these three, two are private limited banks and the next one is a foreign joint venture operating in 
Nepal. Surprisingly, Civil Bank has applied a maximum of seven rhetorical devices mixing both schemes and tropes in its slogan. Following it, NIC Asia has applied six devices mixing both tropes and schemes and Kumari Bank has used six devices but all the devices uniquely fall under schemes. Prime bank has used five devices mixing three tropes and two schemes. The remaining four slogans have applied four figures, three slogans applying three figures, and finally, five slogans capturing two figures and the remaining other slogans applying singular figures. While analyzing the use of schemes and tropes, Civil Bank has implied six schemes out of seven figures. As Kumari, Janata Bank has used all four schemes out of four figures, and Mega and Century Bank have also used only schemes out of multiple figures in their slogans. Differently, the slogans of Himalayan and Prabhu Bank have applied only tropes among the multiple figures. Moreover, the slogans from SBI, Agricultural Development, and Citizen have equally four figures in their slogans sharing tropes and schemes.

\section{Figure 2}

\section{Ten Banks Using the Maximum Rhetorical Devices}

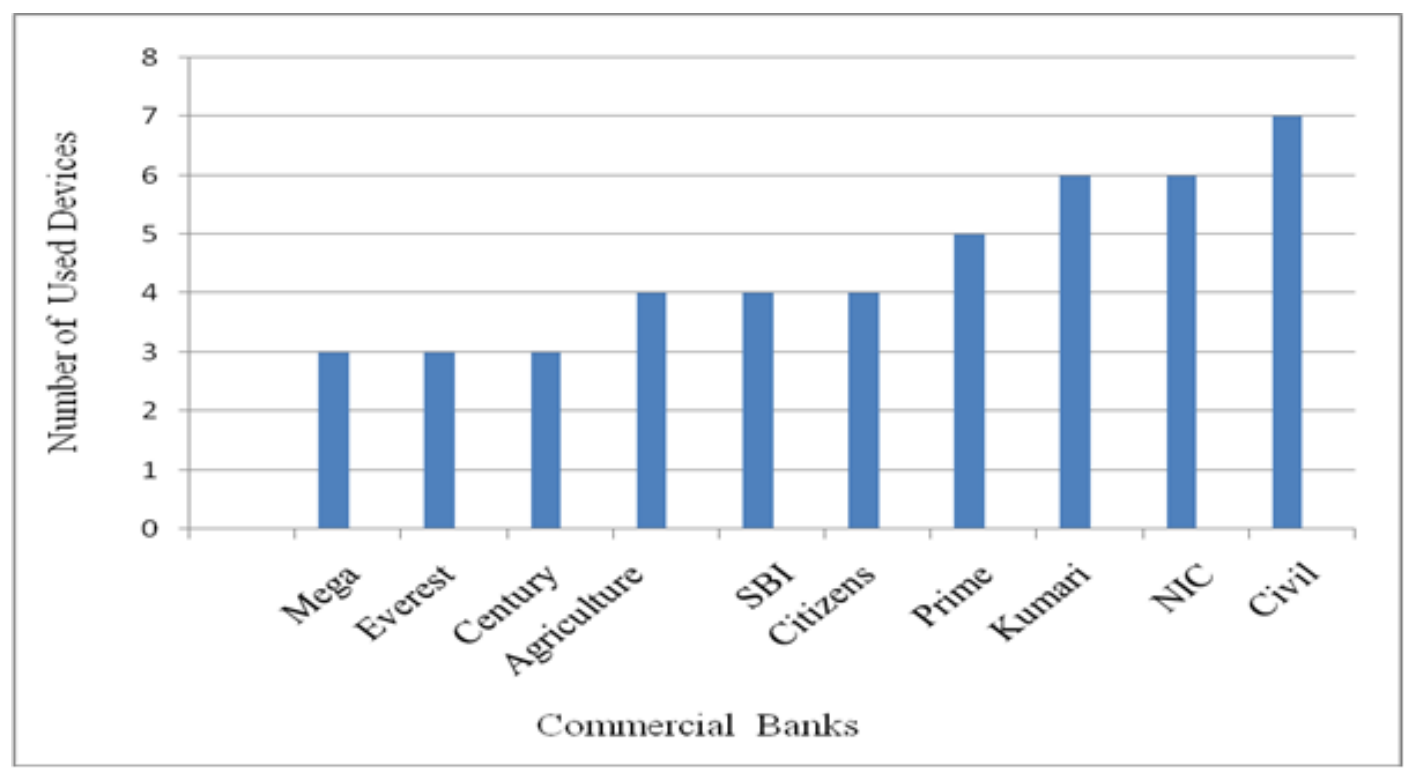

\subsection{Frequency Distribution of Schemes}

As the result of most of the studies cited in the literature review section, the study also reveals the hegemony of the schemes in the slogans selected for this study. Figure 3 presents the results of this study. According to the results of the study, grammatical structures (schemes) are highly preferred in slogans in comparison to tropes. Among schemes, alliteration and parallelism have a maximum repetition of eight times. Subject to the 50 usages of the devices by the domestically owned private commercial banks as already shown in Figure 1, there are 39 usages of schemes and 11 usages of tropes disregarding the higher number of tropes in a theoretical framework. Differently, the foreign joint venture and governmental banks have shared an equal number of tropes and schemes out of 12 and 6 usages respectively. It indicates the fascination of 
slogan designers and choices of Nepal banking to grammatical structures, which offer music, impression, emphasis, attention and urgency.

\section{Figure 3}

Percentage and the Frequency of the Schemes

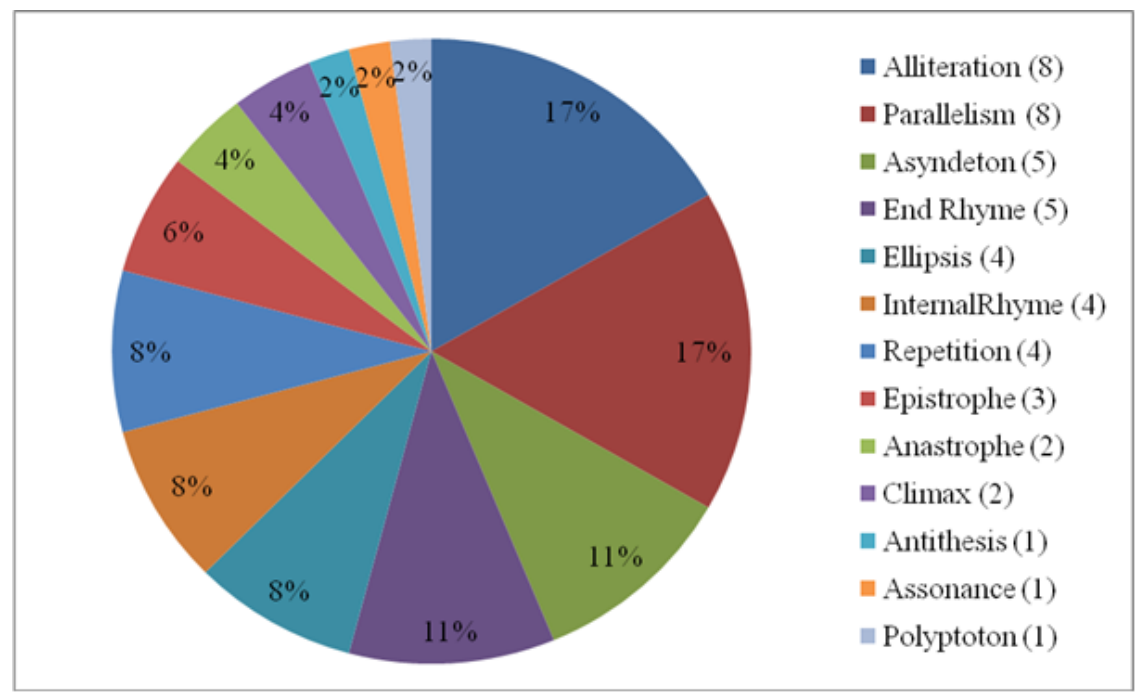

\subsection{Frequency Distribution of Tropes}

In comparison to the list of exercised schemes in the study, the list of used tropes is very short. There are seven devices, which are repeated four or more than four times in case of schemes. However, in tropes, the list is only of three concerning the same degree of frequency.

In terms of frequency distribution among tropes, hyperbole is the most popular device that repeats 6 times in different slogans (Figure 4). Subsequently, personification and metaphor have repeated equal 4 times. Out of the total 20 usages of tropes in this study, these three devices have covered exactly 70 percent space that becomes just about 21 percent among total rhetorical usages according to the theoretical framework. Both the usages and frequency of different schemes are excessively high in comparison to tropes. Only three figures of speech are used once among 13 employed figures in case of schemes but four such devices are used once among eight exercised devices in case of tropes. The frequency of the most repeated slogan is eight in the case of schemes but it decreases in the case of tropes to six.

Remarkably, 13 tropes out of 21 and 7 schemes out of 20 from the theoretical framework are not used in the selected slogans. In this regard, nearly 62 percent of tropes and 35 percent of schemes have not utilized any slogan. Frequent use of hyperbole, personification and metaphor might be for emphasizing the ideas, capturing attention, and communicating the emotion of the concerned user.

Paronomasia, antanaclasis, other types, simile, allusion, parody, paradox, oxymoron, irony, onomatopoeia, metonymy, euphemism, and rhetorical question from the tropes remained unused. Likewise, apposition, polysyndeton, parenthesis, antimetabole, anaphora, anadiplosis, and epanalepsis have no use in any slogans among schemes in this study. Out of 28 slogans selected for the study, 25 slogans have rhetorical devices. Among them, seven slogans have a singular 
trope or scheme because of having a single figure. Furthermore, 10 slogans have used only tropes or schemes even if they have multiple figures.

\section{Figure 4}

Frequency of the Tropes

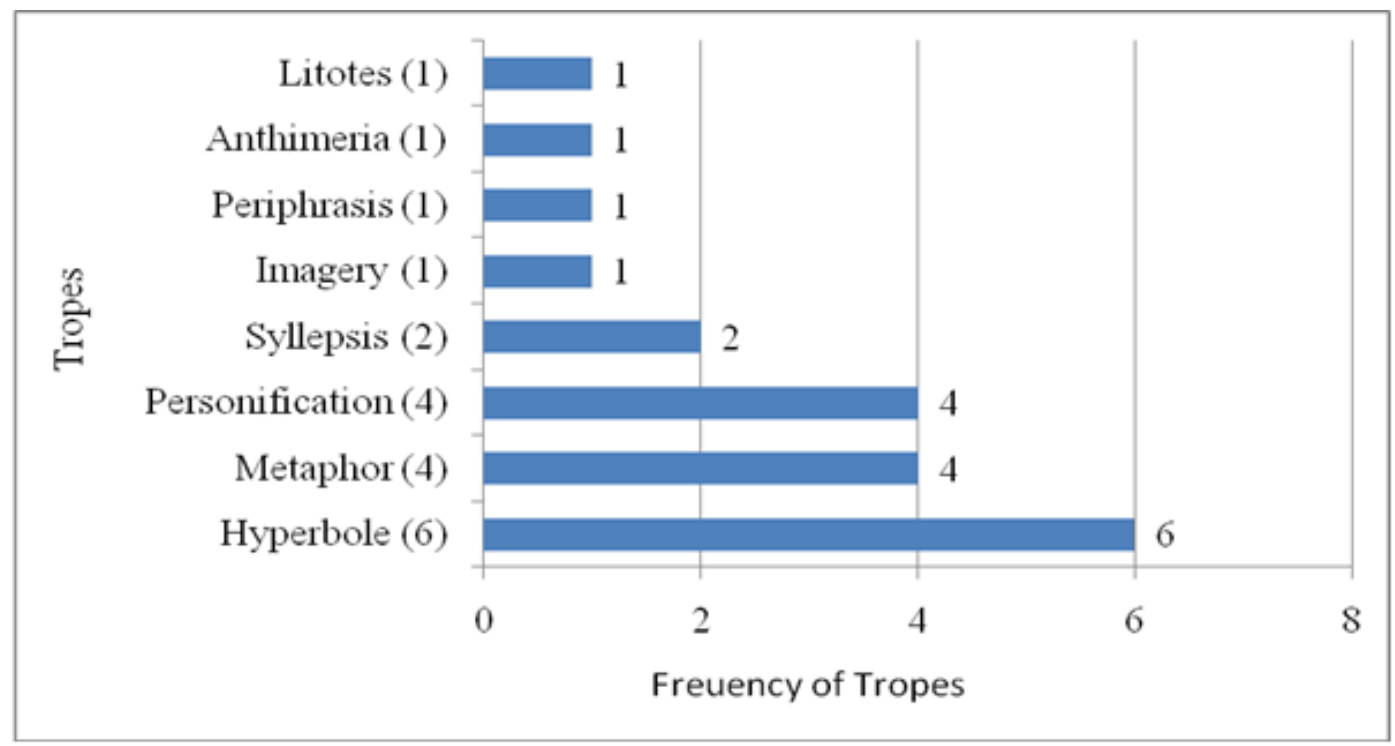

Moreover, the presence of one figure seems to demand another figure. For instance, alliteration is followed by asyndeton, end rhyme and parallelism. Similarly, hyperbole and metaphor as well as personification and parallelism are appearing together in the same slogans. It demands extensive study that incorporates maximum samples to infer possible strong correlations.

\section{DISCUSSIONS}

This descriptive analysis has revealed that private commercial banks deserve mastery in incorporating maximum rhetorical figures in their advertising slogans. It is similar to the idea established by Gupta and Mittal (2008), who has conducted a comparative study of promotional tactics implemented by public and private banks in India. They found "public sector banks do not go for innovative strategies of promotion, however, they go for interactive marketing through the internet but that is not promoted so much like private sector banks" (p. 88). Generally, Rhetoric is used for arousing affect and people think that the advertising of private banks are more effectual than public banks which is scored 3.51 for 5 (Gupta \& Mittal, 2008). In this study too, among the list of 10 banks using maximum devices, only one of them is governmental, two are foreign joint ventures and the remaining all seven are Nepali private banks. It indicates that these private banks are one-step forward than other categories of a bank in utilizing rhetorical devices for effective delivery of a symbolic message.

The strength of sound patterning as suggested by Leigh (1994) and Pogacar (2015) seems to be exactly utilized by the slogans in this study. One of the highest repetitions of alliteration warrants it. Iswati and Widodo (2020) believe that the strength of sound patterning in any slogan is directly proportional to the height of the brand. Phonetically, the pervasiveness of alliteration is 
the prevailing evidence in the study of too. Moreover, the maximum use of parallelism in different slogans contributes to strengthening the rhythm (Skračić \& Kosović, 2016). Similarly, Asyndeton and end rhyme have been repeated five times and ellipsis, repetition and internal rhyme have been repeated equally four times. The repetition of Asyndeton justifies the conclusion of Iswati and Widodo (2020) where Asyndeton comes as the most frequent rhetorical device. Out of nearly 71 percent occupancy of schemes among the total 68 usages of rhetorical devices in this study, only seven devices have captured about 79 percent space among of schemes. These seven devices also cover clear majority in terms of total usages. Contrary to the study of Monsefi and Madadi (2016) and similar to the study of Miller and Toman (2014) this study has detected that the grammatical structures, which is generally understood as schemes, are preferred more than two times in association to tropes. In a qualitative analysis of the slogans up to 1950s and after 1950s, Christopher (2013) has revealed the shifting dominance of tropes in slogans of the later decades, but the study falsifies that and comes with different result where the usage of tropes is limited in comparison to schemes.

The linguistic reading of English advertising slogans in yachting by Skračić and Kosović (2016) has also exposed that metaphor, metonymy, hyperbole and antithesis as the often-used figurative speech and it is comparable to the study where hyperbole and metaphor are the most frequent tropes. Furthermore, unlike advertising contents in other sectors, yachting slogans rarely exercise personification but it is the commonly practiced tropes in this study. On the other hand, metonymy does not appear in these banking slogans, which has covered the larger space in the slogans studied by Monsefi and Mahadi (2016). The metaphor mainly represents the association. Musté et al. (2015) connect deeply laden use of metaphorical language to 'latent associations' and 'emotional bonding power'.

In this context, it indicates the intention of the copywriters to associate a maximum customer with their banking services using metaphors in slogans. Equally, hyperbole contains an overstatement for stress (Cuddon, 1998) and in personification, "an inanimate object or an abstract concept is spoken of as though it is endowed with life or with human attributes or feelings" (Abrams \& Harpham, 2008, p. 121). Ultimately these major three devices serve to emphasize associating emotion to the customer of the banks forcefully.

Exploring the big data using content analysis, Leigh (1994) had identified the combination of tropes and schemes as 'the most common usage' in effective advertising headlines, but only about one-third of slogans of this study has combined these both devices. Even in this combination, schemes have occupied two-third of space there. It is also noticeable that 12 slogans, which are originally in the Nepali language, have consumed more than 50 percent of the total usages of the devices.

\section{CONCLUSIONS}

The result and discussion have indicated that Nepali private commercial banks have mastery in using rhetoric in slogans. In comparison to the foreign joint venture and governmental banks, they have applied maximum devices in their slogans. The result has also signaled that Nepali commercial banks prefer using schemes to tropes as schemes are used more than two times in these slogans. In three categories of the Nepali commercial banks, the slogans of government and foreign joint venture banks have shared an equal number of tropes and schemes, but domestically owned private banks have applied schemes nearly four times more than tropes. It indicates their strong enchantment to foregrounding language deviating grammatical structure. In this course, governmental banks seem to interact with customers as being a public bank, foreign joint venture banks might have been enjoying broader international legacy in their names, but Nepali private banks look smart here in incorporating maximum figures of speech in their slogans to penetrate the sentiment of audience. 
The findings from the descriptive analysis have signaled music, memory, association, emphasis, emotion and exaggeration as some popular constructs for designing the slogans. Moreover, the dominance of sound patterning, hyperbole and metaphor in the slogans seems to work for brand equity. However, the study has only included the slogans of commercial banks from Nepal, but a comparative study between the slogans of all the banks from Nepal and the banks' slogans from other countries may project a clearer picture regarding rhetorical culture than this. However, the study does not incorporate the responses from the audience, so it is not scientific to infer anything about the effectiveness of slogans.

\section{ACKNOWLEDGEMENTS}

The study was accomplished with the support of Faculty Research Grants, Faculty of Management Studies, Pokhara University, Nepal. I would like to acknowledge the financial assistance of the institution for inspiring me for this research. Likewise, I would like to convey my genuine gratitude to those officials of different commercial banks of Nepal who have cooperated with me to collect specific brand slogans of their organization as data for the study.

\section{REFERENCES}

Abrams, M. H., \& Harpham, G. (2008). A Glossary of Literary Terms. Cengage Learning.

Christopher, A. A. (2013). Rhetorical strategies in advertising: The rise and fall pattern. Academic Journal of Interdisciplinary Studies, 2(8), 773-78. http://dx.doi.org/ 10.5901/ajis.2013.v2n8p773

Cuddon, J. A. (1998). The Penguin Dictionary of Literary Terms \& Literary Theory. Penguin.

Denton Jr, R. E. (1980). The rhetorical functions of slogans: Classifications and characteristics. Communication Quarterly, 28(2), 10-18. http://dx.doi.org/10.1080/ 01463378009369362

Durgee, J. F. (1987). Point of view using creative writing techniques in focus groups. Journal of Advertising Research, 26(6), 57-65.

Gupta, S. L., \& Mittal, A. (2008). Comparative Study of Promotional Strategies adopted by Public and Private Sector Banks in India. Asia Pacific Business Review, 4(3), 87-93. https://doi.org/10.1177/097324700800400310

Harris, R. J., Sturm, R. E., Klassen, M. L., \& Bechtold, J. I. (1986). Language in advertising a psycholinguistic approach. Current Issues and Research in Advertising, 9(1-2), 1-26. http://dx.doi.org/10.1080/01633392.1986.10505389

Iarovici, E., \& Amel, R. (1989). The strategy of the headline. Semiotica, 77(4), 441-460. https://doi.org/10.1515/semi.1989.77.4.441

Iswati, L., \& Widodo, P. (2020). Linguistic features in e-commerce slogans. Indonesian Journal of EFL and Linguistics, 5(1), 21-40. http://indonesianefljournal.org/index.php/ijefll/ article/view/211

Kohli, C., Leuthesser, L., \& Suri R. (2007). Got slogan? Guidelines for creating effective slogans. Business Horizons, 50(5), 415-422. https://doi.org/10.1016/ j.bushor.2007.05.002

Lagerwerf, L. (2002). Deliberate ambiguity in slogans: Recognition and appreciation. Document Design, 3(3), 244-260. https://doi.org/10.1075/dd.3.3.07lag

Leigh, J. H. (1994). The use of figures of speech in print ad headlines. Journal of 
Advertising, 23(2), 17-33. https://doi.org/10.1080/00913367.1994.10673439

McQuarrie, E. F., \& Mick, D. G. (1996). Figures of rhetoric in advertising language. Journal of Consumer Research, 22(4), 424-438. https://doi.org/10.1086/209459

Michalik, U., \& Michalska-Suchanek, M. (2016). The persuasive function of rhetoric in advertising slogans. Journal of Accounting and Management, 6(1), 45-58. https://hrcak.srce.hr/162950

Miller, D. W., \& Toman, M. (2014). An analysis of rhetorical figures and other linguistic devices in corporation brand slogans. Journal of Marketing Communications, 22(5), 1-20. https://doi.org/10.1080/13527266.2014.917331

Monsefi, R., \& Mahadi, T. S. T. (2016). Wordplay in English online news headlines. Advances in Language and Literary Studies, 7(2), 68-75. http://journals.aiac.org.au/index. php/alls/article/view/2163

Morgan, S. E., \& Reichert, T. (1999). The message is in the metaphor: Assessing the comprehension of metaphors in advertisements. Journal of Advertising, 28(4), 1-12. https://doi.org/10.1080/ 00913367.1999.10673592

Musté, P., Stuart, K., \& Botella, A. (2015). Linguistic choice in a corpus of brand slogans: repetition or variation. Procedia-Social and Behavioral Sciences, 198, 350-358. https://doi.org/10.1016/ j.sbspro.2015.07.454

Pogacar, R., Plant, E., Rosulek, L. F., \& Kouril, M. (2015). Sounds good: Phonetic sound patterns in top brand names. Marketing Letters, 26(4), 549-563. https://doi.org/10.1007/s11002-014-9288-z

Pryor, K., \& Brodie, R. J. (1998). How advertising slogans can prime evaluations of brand extensions: Further empirical results. The Journal of Product and Brand Management, 7(6), 497-508. https://doi.org/10.1108/10610429810244666

Quelch, J. A., \& Jocz, K. E. (2007). Greater Good: How Good Marketing Makes for Better Democracy. Harvard Business Press.

Skračić, T., \& Kosović, P. (2016). Linguistic analysis of English advertising slogans in yachting. Transactions on Maritime Science, 5(1), 40-47. https://doi.org/10.7225/ toms.v05.n01.005

Stern, B. B. (1988). How does an ad mean? Language in services advertising. Journal of Advertising, 17(2), 3-14. https://doi.org/10.1080/00913367.1988.10673108 


\section{Appendix A}

Framework Concerning the Figures of Speech Developed by James H. Leigh in 1994

\section{Tropes}

I. Puns

1. Antanaclasis

2. Paronomasia

3. Syllepsis

4. Other Types

II. Association
A. Animate Association
1. Allusion
2. Personification
3. Simile
B. Contradictory Association
1. Irony
2. Metaphor
3. Oxymoron
4. Paradox
5. Parody
C. Visual Associations through Word
1. Imagery
2. Onomatopoeia
D. Verbal Substitution
1. Anthimeria
2. Metonymy
3. Periphrasis

E. Exaggerations and Understatements

1. Euphemism

2. Hyperbole

3. Litotes

F. Rhetorical Questions

\section{Schemes}

A. Word Order-Coordinated

1. Anastrophe

2. Antithesis

3. Apposition

4. Climax

5. Parallelism

B. Deliberate Word Omissions and Insertions

1. Asyndeton

2. Ellipsis

3. Parenthesis

4. Polysyndeton

C. Repetitions

1. Alliteration

2. Anadiplosis

3. Anaphora

4. Antimetabole

5. Assonance

6. Epanalepsis

7. Epistrophe

8. Polyptoton

9. Repetition

D. Rhyme

1. End Rhyme

2. Internal Rhyme 